\title{
Geociências
}

\section{Caracterização Mineralógica das Argilas da Península de Santa Elena, Equador}

\author{
(Mineralogical charaterization of the clays of the Santa Elena \\ Peninsula, Ecuador)
}

\author{
Ana Mercedes Morales Carrera \\ Doutoranda-DEGEO/UFOP. Ouro Preto/Brasil \\ FICT/ESPOL. Campus Gustavo Galindo, Km30.5 vía Perimetral. Ap.:09-01-5863. Guaiaquil-Equador \\ E-mail:anamc73@gmail.com \\ Angélica Fortes Drummond Chicarino Varajão \\ Professora Associada - Departamento de Geologia/UFOP - Ouro Preto - MG - Brasil \\ E-mail: angelica@degeo.ufop.br \\ Marcos Andrade Gonçalves \\ Professor Adjunto - ICEB/UFOP - Ouro Preto - MG - Brasil \\ E-mail:marcos.andrade@iceb.ufop.br
}

\section{Resumo}

A Península de Santa Elena, localizada a sudoeste do litoral equatoriano, é formada por rochas ígneas e sedimentares do Cretáceo até o Quaternário. As argilas pesquisadas são provenientes da alteração de cinzas vulcânicas andinas e encontram-se inseridas nos argilitos das unidades do Eoceno Médio ao Mioceno Médio (Grupo Ancón, Formações Tosagua e Progreso).

Análises mineralógicas (DRX, ATG e ATD), análises texturais (distribuição granulométrica, superfície especifica e estudo morfológico por microscopia eletrônica de varredura) e análises químicas (fluorescência de raios-X e capacidade de troca catiônica) permitiram a seleção de quatro depósitos, cujo principal argilomineral é a montmorilonita com ferro, em associação com caulinita e traços de mica. As argilas desses depósitos foram caracterizadas como bentonitas cálcicas.

Palavras-chave: Argila, montmorilonita, bentonita, Península Santa Elena, Grupo Ancón, Formação Tosagua.

\begin{abstract}
The Santa Elena Peninsula, located in the southwest of the Ecuadorian coast, consists of igneous and sedimentary rocks from the Cretaceous to the Quaternary era. The sampled clays originated from the alteration of Andean volcanic ashes found inserted in the clay rocks of the Eocene Medium to Miocene Medium (Ancon Group and, Tosagua and Progreso Formations).

Mineralogical analysis (XDR, ATG and ATD), textural analysis (grain size distribution, specific surface and morphological analysis by SEM), and chemical analysis (X-ray fluorescence and CEC), have permitted the selection of four deposits that have ironmontmorillonite as their main clay mineral, in association with kaolinite and traces of mica. Clays of theses deposits have been characterized as calcic bentonites.
\end{abstract}

Keywords: Clay, montmorillonite, bentonite, Santa Elena Peninsula, Ancon Group, Tosagua Formation. 


\section{Introdução}

A Península de Santa Elena localiza-se a sudoeste do litoral equatoriano (Figura 1), abrangendo uma área de, aproximadamente, $12.000 \mathrm{~km}^{2}$. Nela encontram-se várias ocorrências de minerais e rochas industriais, tais como materiais argilosos, calcários, gipsita, lutitos diatomáceos e outros materiais de construção, sendo os primeiros os mais abundantes. Estes se encontram inseridos no Grupo Ancón e nas Formações Tosagua e Progreso (Spencer, 1993; Dugas, 1986; Del Arco et alii, 1983; Bristow et alii, 1977) do Eoceno Médio ao Mioceno Médio.

O Grupo Ancón (Figura 1), com uma espessura estimada em $1.500 \mathrm{~m}$, aflora, principalmente, na bacia Ancón, no sul da Depressão Chongón-Colonche e, em alguns pontos da Cordilheira ChongónColonche. Garner (1956, in Del Arco et alii, 1983) propôs a divisão desse grupo nas Formações Socorro e Seca. A Formação Socorro é subdividida nos Membros Clay Pebble Bed e Socorro, enquanto a Seca, nos Membros Lutita Seca e Arenisca Punta Ancón. O Membro Clay Pebble Bed é formado por argilito, quartzito, conglomerado, chert, rochas ígneas, calcário, arenito turbidítico e fragmentos de rochas das formações preexistentes. O Membro Socorro é constituído por lutitos turbidíticos, arenito e argilito. O Membro Lutita Seca é formado por lutitos turbidíticos e arenitos. O Membro Arenisca Punta Ancón constitui-se de arenito grauvaquiano com intercalações de argilitos, conglomerados com linhito, calcário e lutitos.

A Formação Tosagua (Figura 1) é constituída por três membros. O Membro Zapotal, com uma espessura de até 1.100 m, é constituído por conglomerado com seixos de quartzo, arenito com tufos e lutitos em uma matriz argilosa. $\mathrm{O}$ Membro Dos Bocas possui uma espessura máxima estimada de 2.000 m e é formado, principalmente, por argilitos de cor marrom em camadas centimétricas a decimétricas, com intercalações de finos estratos de gipsita e arenito. O Membro Villingota é constituído por lutitos diatomáceos de cor branca ou creme, com escamas de peixes e microfósseis; sua espessura é de até $300 \mathrm{~m}$.

A Formação Progreso (Figura 1) possui uma espessura máxima de $2.700 \mathrm{me}$ é formada por arenitos, siltitos, argilitos e calcários com restos de moluscos.
Apesar da extensa distribuição dos materiais argilosos na península, os estudos relativos ao seu aproveitamento têm sido feitos em pequena escala e de maneira rudimentar. Os referidos materiais argilosos são utilizados, principalmente, como aditivo na fabricação de

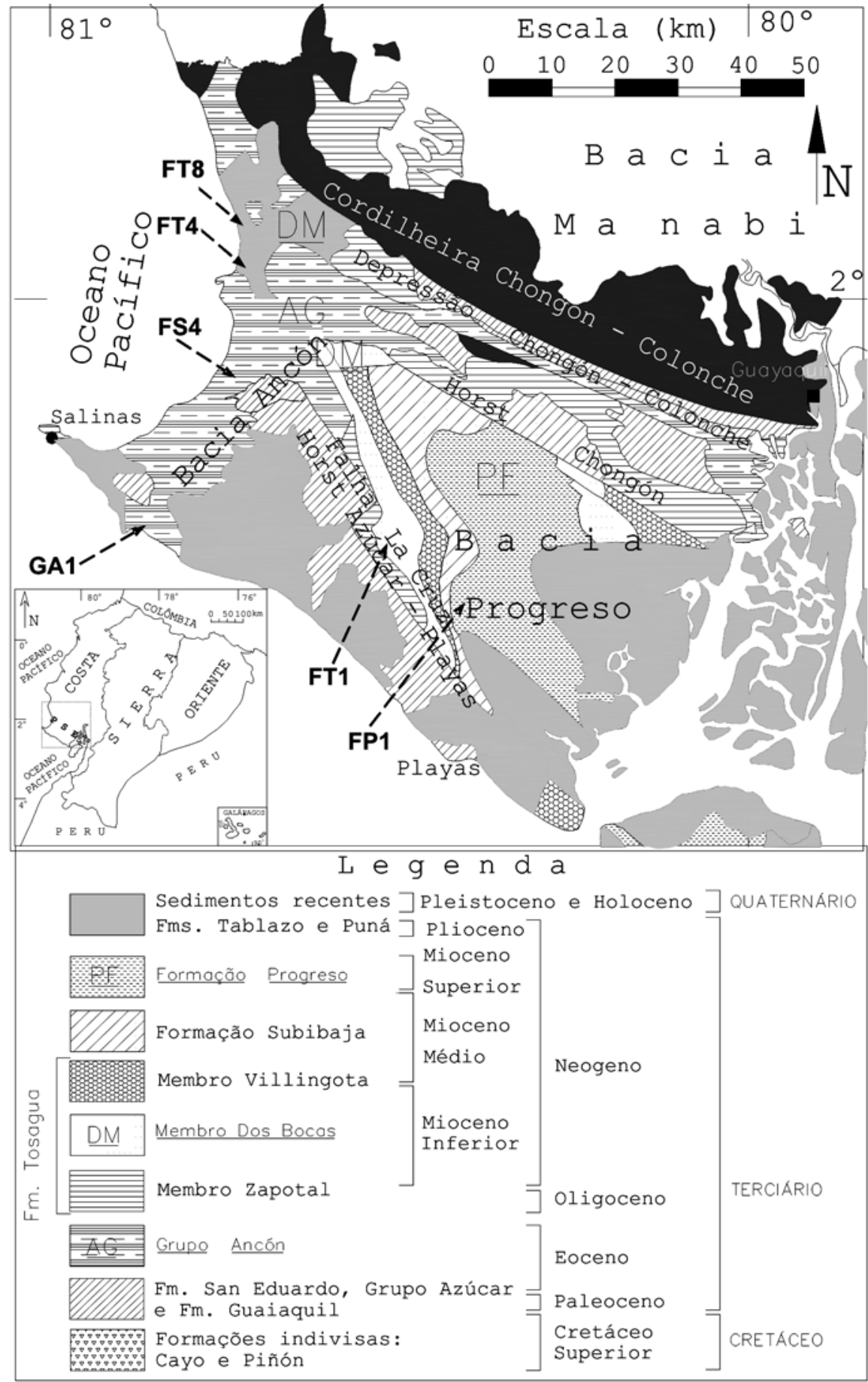

Figura 1 - Localização e coluna estratigráfica da Península de Santa Elena, indicando as amostras selecionadas do Grupo Ancón (GA1 e FS4) e Formações Progreso (FP1) e Tosagua (FT1, FT4 e FT8) (Spencer, 1993). 
cimento (CODIGEM, 1997) e na confecção de objetos cerâmicos (Muff \& Kapteinat, 1988).

Relatórios internos (Holderbank, 1974) de trabalhos relacionados à pesquisa de matérias-primas para a fabricação de cimento, em áreas próximas a Guaiaquil, foram os primeiros estudos mineralógicos e químicos que incluíram as argilas do litoral equatoriano. Entretanto a primeira caracterização mineralógica e tecnológica das argilas litorâneas foi realizada em uma única jazida de argila do Grupo Ancón próxima a Guaiaquil (Morales-Carrera, 2003; Morales-Carrera et alii, 2003). Tal estudo, além de identificá-la como bentonita cálcica, permitiu conhecer o seu potencial para aplicações tecnologicamente mais avançadas, após sua ativação ácida.

Considerando a abundância de materiais argilosos na península e os resultados já obtidos em uma única jazida da região, o presente trabalho visou a estender o estudo de caracterização mineralógica, física e química e de avaliação do potencial de aplicação para os materiais argilosos da Península de Santa Elena. As amostras selecionadas nesse trabalho estão inseridas nos membros Clay Pebble Bed (GA1) e Socorro (FS4) da Formação Socorro (Grupo Ancón), no Membro Dos Bocas (FT1, FT4 e FT8) da Formação Tosagua e, na Formação Progreso (FP1), por apresentarem maior conteúdo argiloso.

Estudos sobre evolução geológica da Costa do Equador (Dorfman, 1976; Lonsdale, 1978) revelaram, no Cretáceo, a ocorrência de atividades vulcânicas com deposição de tufos e outros fragmentos de rochas e sedimentos marinhos, juntamente com eventos tectônicos, que antecedem a deposição dos sedimentos do Grupo Ancón e Formações Tosagua e Progreso. Tal fato sugere que as argilas em estudo, podem ter sido produto de alteração de cinzas vulcânicas, podendo, portanto serem definidas, genericamente, como bentonitas, que é a denominação mais utilizada desde 1917 (Moore \& Reynolds, 1989), devido a tal origem.

\section{Metodologia}

A pesquisa iniciou com o reconhecimento de 188 afloramentos, distribuídos aleatoriamente na península, das unidades litológicas do Grupo Ancón e das Formações Tosagua e Progreso. A partir das observações de campo, 42 amostras foram coletadas, por conterem maior proporção da fração argila, maior plasticidade e menor proporção de minerais não-filossilicatos.

Todas as 42 amostras foram secas a $60^{\circ} \mathrm{C}$ de temperatura durante 24 horas, moídas em almofariz de ágata e analisadas mineralógica e quimicamente. A análise mineralógica foi realizada usando um difratômetro RIGAKU GEIGERFLEX D/MAX com radiação monocromática de $\mathrm{CuK} \alpha$ e velocidade do goniômetro de $1.2^{\circ}$ por minuto ${ }^{-1}$ para a fração pó total e de $0.6^{\circ}$ por minuto ${ }^{-1}$ para a fração argila (fração $<2 \mu \mathrm{m}$ ), separada por sedimentação. Os difratogramas obtidos na fração total abrangem um intervalo de 2 a $70^{\circ}(2 \theta)$ e das amostras orientadas da fração argila de 2 a $35^{\circ}(2 \theta)$. Os elementos maiores foram analisados por fluorescência de raios $\mathrm{X}$, utilizando um espectrômetro Magi X, equipado com o software SuperQ, versão 3.

A partir dos difratogramas das frações total e argila, foram selecionadas 6 amostras (Figura 1), por apresentarem as maiores intensidades para os picos $d(001)$ do grupo das esmectitas: GA1 e FS4 (Grupo Ancón), FT1, FT4 e FT8 (Formação Tosagua) e FP1 (Formação Progreso).

Para as 6 amostras selecionadas, após extração dos carbonatos e da matéria orgânica, procedeu-se à análise granulométrica (EMBRAPA, 1997; Mato et alii, 1982) e determinação das frações areia $(>0,053 \mathrm{~mm}$ e $<2 \mathrm{~mm})$, silte $(>0,002 \mu \mathrm{m}$ e $<0,053 \mu \mathrm{m})$ e argila $(<2 \mu \mathrm{m})$. A fração argila foi submetida à saturação com $\mathrm{MgCl}_{2}, \mathrm{KCl}$ (Walker, 1958 in Brown, 1961) e LiCl (Greene-Kelly, 1953a) e, novas análises de DRX, amostras desorientadas e orientadas, foram efetuadas para determinação da espécie de argilomineral.
Análises termodiferenciais (ATD) e termogravimétricas (ATG) foram efetuadas sobre a fração argila natural de 4 amostras selecionadas, após a extração dos óxidos e hidróxidos de ferro amorfos e cristalinos segundo o método DCB, ditionito-citrato-bicarbontato (Mehra \& Jackson, 1960). O equipamento utilizado foi da TAINSTRUMENTS, modelo 2960 STD V2.2B, com taxa de aquecimento de $10^{\circ} \mathrm{C}$ por minuto, atmosfera de $\mathrm{N}_{2}$ e temperatura máxima de $1.100^{\circ} \mathrm{C}$.

A espectrometria no infravermelho foi realizada no Laboratoire Environnement et Minéralurgie (LEM) da Escola Nacional de Geologia de Nancy (França), num espectrômetro com transformada de Fourier (Brucker IFS 55), por transmissão, na fração argila natural das 4 amostras selecionadas, sendo os espectros registrados entre 400 e $4000 \mathrm{~cm}^{-1}$, com resolução de $4 \mathrm{~cm}^{-1}$, através de um detector DTGS - sulfato de triglicina deutério. Para as análises de transmissão, as amostras foram diluídas em $\mathrm{KBr}$ (1 mg de amostra por $150 \mathrm{~g}$ de $\mathrm{KBr}$ ) e homogeneizadas e as pastilhas foram obtidas com uma pressão de 15 toneladas $/ \mathrm{m}^{2}$.

As fotomicrografias foram obtidas no microscópio eletrônico de varredura da JEOL JSM-5510, de 0.5 a $30 \mathrm{Kv}$, com resolução de 3,5 a $48 \mathrm{~nm}$ e metalização de grafite.

A capacidade de troca catiônica e a superfície específica total foram quantificadas usando o método azul de metileno (Pejon \& Zuquette, 1992). A densidade foi determinada usando um MultiPicnômetro da QUANTACHROME, sendo Hélio o gás usado. A superfície específica externa foi determinada pelo método BET(Brunauer, Emmett \& Teller, 1938) com adsorção de $\mathrm{N}_{2} \mathrm{a}-196^{\circ} \mathrm{C}$, sendo a amostra desgaseificada a $60^{\circ} \mathrm{C} \mathrm{du}-$ rante 5 horas. O equipamento utilizado foi High Speed Gas Sorption da QUANTACHROME, modelo NOVA 1000. Argilas contendo montmorilonita possuem, além da superfície externa, uma superfície interna entre as camadas que não é accessível ao $\mathrm{N}_{2}$ (Greene-Kelly, 1964; Diamond \& Kinter, 1956). A metodologia usando azul de metileno permite 
quantificar, tanto a capacidade de troca catiônica da montmorilonita, quanto a sua superfície específica total, pois, em solução líquida, íons de azul de metileno podem entrar entre as camadas que formam sua estrutura cristalina (Kahr \& Madsen, 1995).

\section{Resultados e discussão}

A Tabela 1 mostra a distribuição granulométrica das 6 amostras selecionadas. A amostra FS4 do Grupo Ancón contém a maior percentagem de argila ( $<2 \mu \mathrm{m})$, com 62,13\%; seguida da FT1, com 51,11 \% e FT8 com 44,15\%, ambas da Formação Tosagua. As amostras FT4, GA1 e FP1 apresentam os percentuais mais baixos em argila (<25\%), que são compensados pelos maiores teores em silte.

Concentrações mais elevadas em silte podem ter relação com certa aglomeração de partículas de argilominerais, pois, apesar de seguidos os procedimentos de eliminação da matéria orgânica e carbonatos (EMBRAPA, 1997), os difratogramas de raios $\mathrm{X}$ obtidos da fração silte, com amostras orientadas, revelaram a presença marcante de argilominerais do grupo das esmectitas. Aglomerados podem ser claramente observados, mesmo na fração argila (Figura 2), através das análises de microscopia eletrônica de varredura (MEV).

Os difratogramas da fração total das seis amostras representativas do Grupo Ancón e das Formações Tosagua e Progreso (Figura 3A) indicam a presença marcante de argilominerais do grupo das esmectitas. Nesses difratogramas também se observam traços de outros minerais argilosos como mica e caulinita. Minerais não-argilosos como quartzo e feldspato estão sempre presentes e, em algumas amostras, tem-se calcita e gipsita.

Os difratogramas da fração argila (Figura 3B) dessas mesmas seis amostras mostram a maior intensidade do pico a 15 Å e, portanto, a predominância do

Tabela 1 - Distribuição granulométrica das seis amostras representativas do Grupo Ancón e das Formações Tosagua e Progreso.

\begin{tabular}{c|c|c|c|c}
\hline $\begin{array}{c}\text { Unidade } \\
\text { litológica }\end{array}$ & Amostra & Argila (\%) & Silte (\%) & Areia (\%) \\
\hline \multirow{2}{*}{ Grupo Ancón } & GA1 & 22,66 & 66,64 & 10,7 \\
\cline { 2 - 5 } & FS4 & 62,13 & 33,62 & 4,25 \\
\hline \multirow{2}{*}{$\begin{array}{c}\text { Formação } \\
\text { Tosagua }\end{array}$} & FT1 & 51,11 & 47,36 & 1,53 \\
\cline { 2 - 5 } & FT4 & 23,26 & 70,54 & 6,2 \\
\cline { 2 - 5 } & FT8 & 44,15 & 50,22 & 5,63 \\
\hline $\begin{array}{c}\text { Formação } \\
\text { Progreso }\end{array}$ & FP1 & 11,51 & 70,98 & 17,51 \\
\hline
\end{tabular}
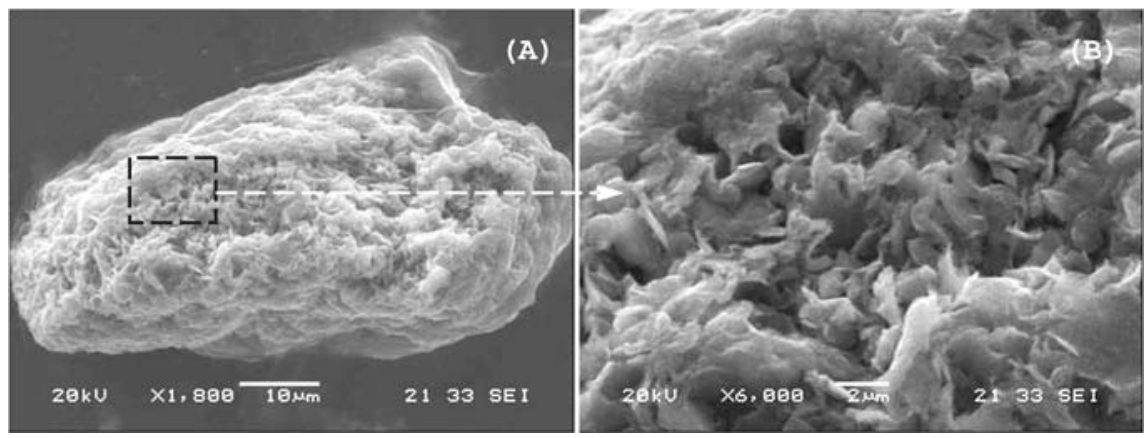

Figura 2 - Fotomicrografias obtidas por microscopia eletrônica de varredura da fração argila da amostra GA1. (A): Um aglomerado; (B) detalhe da região assinalada no aglomerado mostrando lamelas típicas das esmectitas aglomeradas.

argilomineral do grupo das esmectitas. Associa-se, também, a essa fração a presença de caulinita e traços de ilita. Adicionalmente, ocorrem quartzo e traços de calcita e feldspato. Nas amostras GA1 e FS4, ocorre, também, a presença de goethita (Figura 3B). Difratogramas das amostras da fração argila, desorientadas, revelaram valores do pico $d(060)$ de $\sim 1.49 \AA$, o que caracteriza a presença de minerais do grupo das esmectitas dioctaédricas, cujas principais variedades são montmorilonita, com carga da camada originada a partir de substituições na folha octaédrica, e a série beidelita-nontronita, cujas cargas das camadas são originadas a partir de substituições na folha tetraédrica (Brindley \& Brown, 1980; Moore \& Reynolds, 1989). Entretanto, segundo Brindley e Brown (1980, p. 170), composições intermediárias entre montmorilonita, em um lado da série, e beidelita-nontronita, em outro lado, são comuns.
Após saturação com $\mathrm{MgCl}_{2}$ (Figura 4A), valores de $d(001)$ próximos a $15 \AA$, nas amostras secas à temperatura ambiente, passam a $18 \AA$, ao serem saturadas com glicerol, e a $10 \AA$, ao serem aquecidas a $350^{\circ} \mathrm{C}$. Quando da saturação com $\mathrm{KCl}$ (Figura 4B), valores de d (001) próximos a $12 \AA$, nas amostras secas ao ambiente, passam a $14 \AA$, ao serem saturadas com glicerol, e a valores próximos a $10 \AA$, quando aquecidas a $350^{\circ} \mathrm{C}$ e $550^{\circ} \mathrm{C}$. Tais resultados confirmam a presença do argilomineral do grupo das esmectitas. Para determinar a origem da carga das camadas, se tetraédrica ou octaédrica, de modo a distinguir a montmorilonita da beidelita e nontronita, utilizou-se a metodologia de Greene-Kelly (1953a), na qual a fração argila foi saturada com LiCl. Deste modo, a montmorilonita pode ser diferenciada da beidelita e nontronita pelo seu irreversível colapso depois de aquecida após a saturação com Li. O íon Li migra para a folha octaédrica e neutraliza 


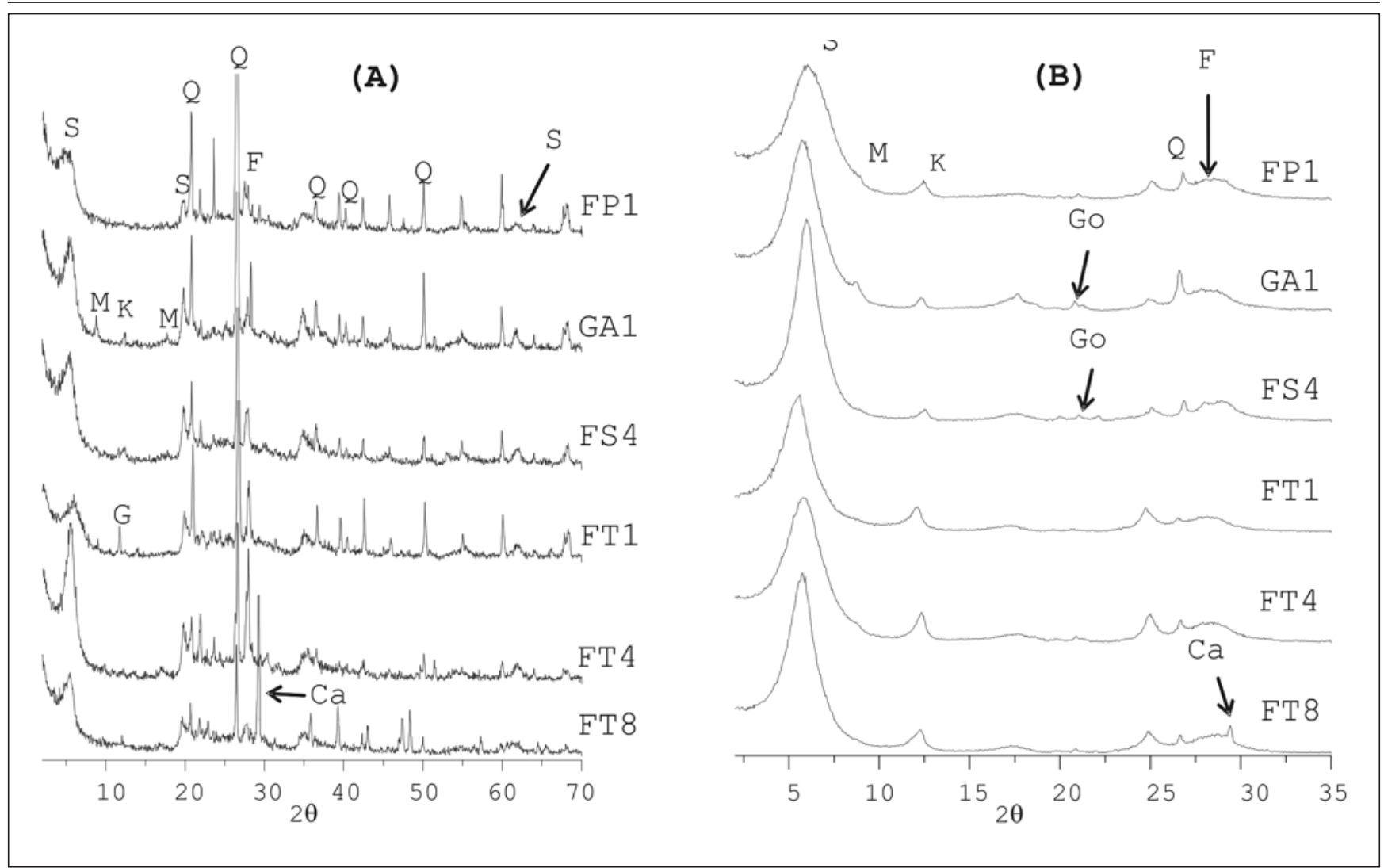

Figura 3 - Difratogramas mostrando a mineralogia da fração total (A) e da fração argila (B) das 6 amostras selecionadas do grupo Ancón e das formações Progreso e Tosagua. Sendo S: esmectita, M: mica, K: caulinita, Q: quartzo, F: feldspato, Ca: calcita, G: gipsita. Observa-se a presença de Go - goethita - na fração argila das amostras GA1 e FS4.

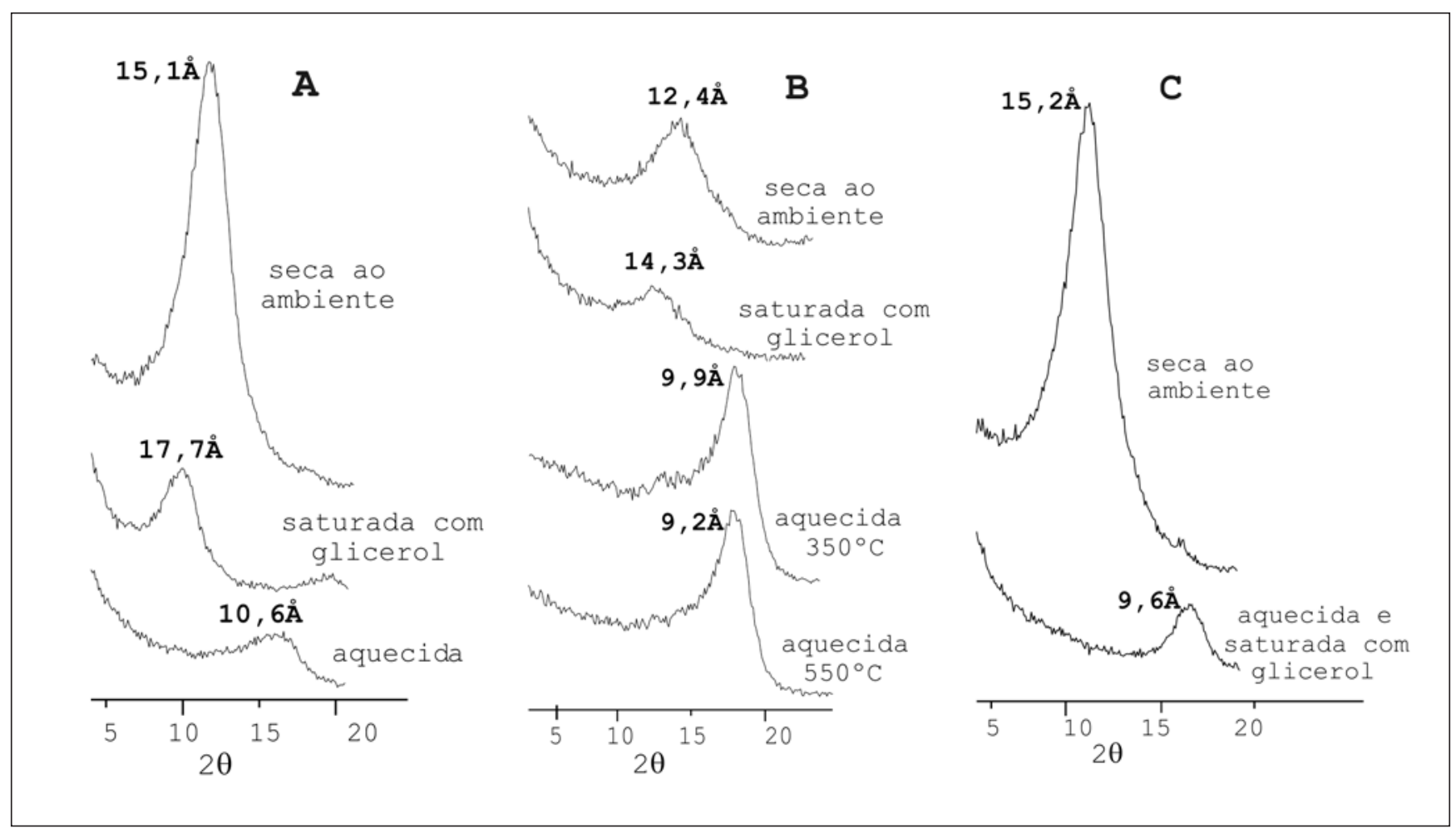

Figura 4 - Difratogramas da fração argila (amostra FT1) após saturação com $\mathrm{MgCl}_{2}$ (A), com $\mathrm{KCl}$ (B) e com $\mathrm{LiCl}(\mathbf{C})$. 
a carga da camada, se essa carga é devida a substituição octaédrica. A eliminação da carga converte a montmorilonita, em um mineral com as mesmas características da pirofilita, isto é, um mineral que não expande quando saturado com água ou ethileno glicol ou glicerol.

Os difratogramas obtidos da fração argila (Figura 4C) após a saturação com $\mathrm{LiCl}$, aquecimento a $300^{\circ} \mathrm{C}$ por $12 \mathrm{~h}$ e, novamente, saturação com glicerol mostraram valores de $d(001)$ próximos a 9,6 , evidenciando o colapso do argilomineral e, conseqüentemente, a sua identificação como montmorilonita.

As análises térmicas diferenciais (Figura 5) mostram comportamentos térmicos da fração argila, após a extração dos óxidos e hidróxidos de ferro, das 4 amostras que foram selecionadas após análises por difração de raios X. Os dois primeiros picos endotérmicos $\left(\sim 70^{\circ} \mathrm{C} \mathrm{e}\right.$ $\sim 300^{\circ} \mathrm{C}$ ) são relativos à perda de água adsorvida e água intercamada na esmectita. Na amostra GA1, tem-se, ainda, o pico a $160^{\circ} \mathrm{C}$. Segundo Greene-Kelly (1953b), a presença de dois picos no intervalo de $100-300^{\circ} \mathrm{C}$ se deve a tendência prematura de perda de $\mathrm{H}_{2} \mathrm{O}$ de um íon divalente. O terceiro pico endotérmico a $\sim 470^{\circ} \mathrm{C}$ refere-se à desidroxilação da caulinita e/ou esmectita. Os picos endotérmicos a $\sim 720^{\circ} \mathrm{C}$ e $870^{\circ} \mathrm{C}$ referem-se a esmectita. As curvas termogravimétricas apresentam uma perda total de massa no final do aquecimento, entre 16 e $24 \%$.
Resultados de análises químicas (Tabela 2) mostram, para a fração argila, razão $\mathrm{SiO}_{2} / \mathrm{Al}_{2} \mathrm{O}_{3}$ superior a 2 , compatível com a predominante presença de montmorilonita (Gomes, 1986). Na fração pó total, elevados teores de $\mathrm{SiO}_{2}$ referem-se à presença de quartzo e feldspatos. Teores médios de $\mathrm{Fe}_{2} \mathrm{O}_{3}$ de $7 \%$ além de serem relacionados à presença de hidróxidos de ferro, como goethita, podem ser relacionados à presença de Fe no sítio octaédrico, implicando terem essas esmectitas dioctaédricas uma composição intermediária entre as séries montmorilonita e beidelita-nontronita. De fato, os teores de $\mathrm{Fe}_{2} \mathrm{O}_{3}$ nas amostras GA1 e FS4, que mostraram a presença de goethita (Figura 3B), após a extração dos óxido-hidróxidos de ferro, apresentaram, respectivamente, teores de $\mathrm{Fe}_{2} \mathrm{O}_{3}$ de 5,21\% e 4,52 \%, o que sugere a presença deste na estrutura da esmectita.

Comparando as temperaturas de desidroxilação das amostras selecionadas nesse estudo (Figura 5) com as temperaturas típicas de desidroxilação das esmectitas dioctaédricas (Tabela 3), assim como com a bentonita de Wyoming, observa-se que os valores encontrados nesse trabalho são próximos aos da montmorilonita $\left(\sim 700-850^{\circ} \mathrm{C}\right)$. Já para as bentonitas da Paraíba (Brasil), onde teores de ferro são maiores (Amorim et alii, 2004) do que os do presente estudo, ocorre a presença de um pico endotérmico intermediário a $\sim 500-650^{\circ} \mathrm{C}$.

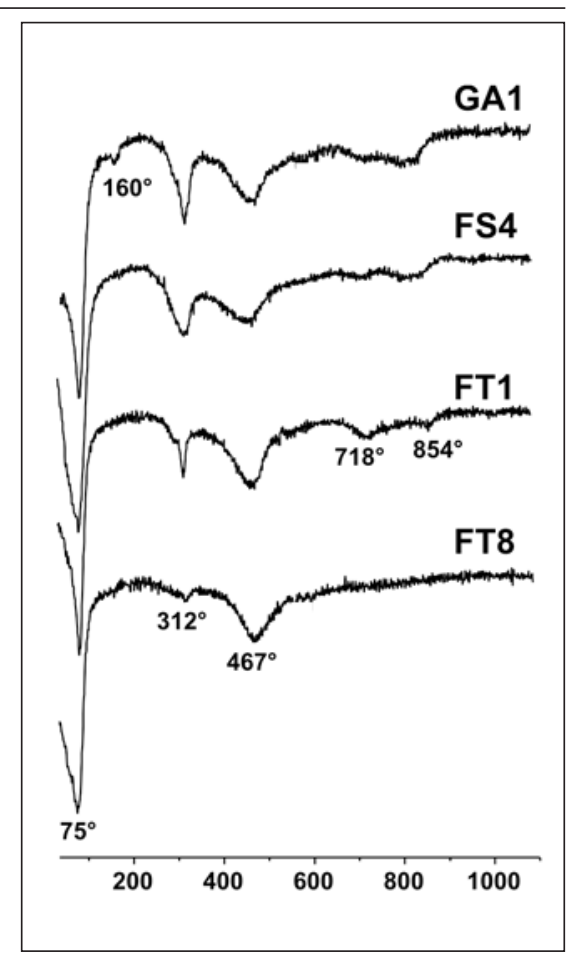

Figura 5 - Curvas termodiferenciais da fração argila das quatro amostras selecionadas, após a aplicação do método DCB.

Na Figura 6, são mostradas as bandas que ocorrem nos espectros do infravermelho das quatro amostras selecionadas, na sua fração argila. Como resultado das substituições isomórficas (tetraédricas e octaédricas) nas esmectitas dioctaédricas, as ordens cristalinas são reduzidas e as imperfeições estruturais são registradas através das bandas de adsorção dos espectros do infraverme-

Tabela 2 - Composição química das frações total e argila das quatro amostras de argila.

\begin{tabular}{|c|c|c|c|c|c|c|c|c|c|c|c|c|}
\hline Amostra & Fração & $\mathrm{SiO}_{2}$ & $\mathrm{Al}_{2} \mathrm{O}_{3}$ & $\mathrm{Fe}_{2} \mathrm{O}_{3}$ & $\mathrm{MgO}$ & $\mathrm{CaO}$ & $\mathrm{K}_{2} \mathrm{O}$ & $\mathrm{Na}_{2} \mathrm{O}$ & $\mathrm{TiO}_{2}$ & $\mathrm{P}_{2} \mathrm{O}_{5}$ & $\mathrm{MnO}$ & LOI \\
\hline \multirow{2}{*}{ GA1 } & Total & 60,53 & 14,40 & 6,03 & 2,12 & 1,22 & 1,76 & 0,99 & 0,71 & 0,13 & 0,03 & 12,08 \\
\hline & Argila & 54,64 & 19,01 & 8,91 & 3,07 & 2,04 & 1,84 & 0,34 & 0,66 & 0,13 & 0,02 & 9,34 \\
\hline \multirow{2}{*}{ FS4 } & Total & 58,19 & 14,60 & 5,72 & 2,03 & 2,03 & 1,39 & 1,31 & 0,63 & 0,15 & 0,06 & 13,89 \\
\hline & Argila & 52,55 & 20,21 & 8,77 & 2,66 & 2,22 & 1,03 & 0,20 & 0,70 & 0,09 & 0,03 & 11,54 \\
\hline \multirow{2}{*}{ FT1 } & Total & 52,36 & 16,67 & 7,40 & 2,03 & 2,24 & 1,15 & 1,06 & 0,76 & 0,12 & 0,07 & 16,14 \\
\hline & Argila & 51,24 & 21,25 & 7,68 & 2,61 & 1,30 & 0,79 & 1,27 & 0,70 & 0,21 & 0,01 & 12,94 \\
\hline \multirow{2}{*}{ FT8 } & Total & 53,45 & 16,19 & 6,58 & 2,07 & 2,69 & 0,91 & 2,02 & 0,61 & 0,30 & 0,02 & 15,16 \\
\hline & Argila & 46,20 & 17,76 & 7,75 & 2,34 & 8,36 & 0,58 & 0,38 & 0,62 & 0,13 & 0,01 & 15,87 \\
\hline
\end{tabular}


Tabela 3 - Comparação entre as temperaturas dos picos endotérmicos para montmorilonita de diferentes proveniências.

\begin{tabular}{|c|c|c|c|c|c|c|}
\hline \multirow{3}{*}{ Proveniência } & \multirow{3}{*}{ Autor } & \multirow{3}{*}{ Ano } & \multicolumn{4}{|c|}{ Reações endotérmicas } \\
\hline & & & \multicolumn{2}{|c|}{$\begin{array}{l}\text { Perda da água adsorvida } \\
\text { (intercamada) }\end{array}$} & \multicolumn{2}{|c|}{ Perda das hidroxilas } \\
\hline & & & \multicolumn{4}{|c|}{ Temperatura $\left({ }^{\circ} \mathrm{C}\right)$} \\
\hline Wyoming - EUA & Mielenz et alii & 1953 & $90-200$ & $200-260$ & $480-740$ & $740-930$ \\
\hline Wyoming - EUA & Mackenzie & 1957 & $170-200$ & $200-230$ & - & $700-900$ \\
\hline Paraíba - Brasil & Amorim et alii & 2004 & $146-188$ & $220-240$ & $500-650$ & $890-930$ \\
\hline
\end{tabular}

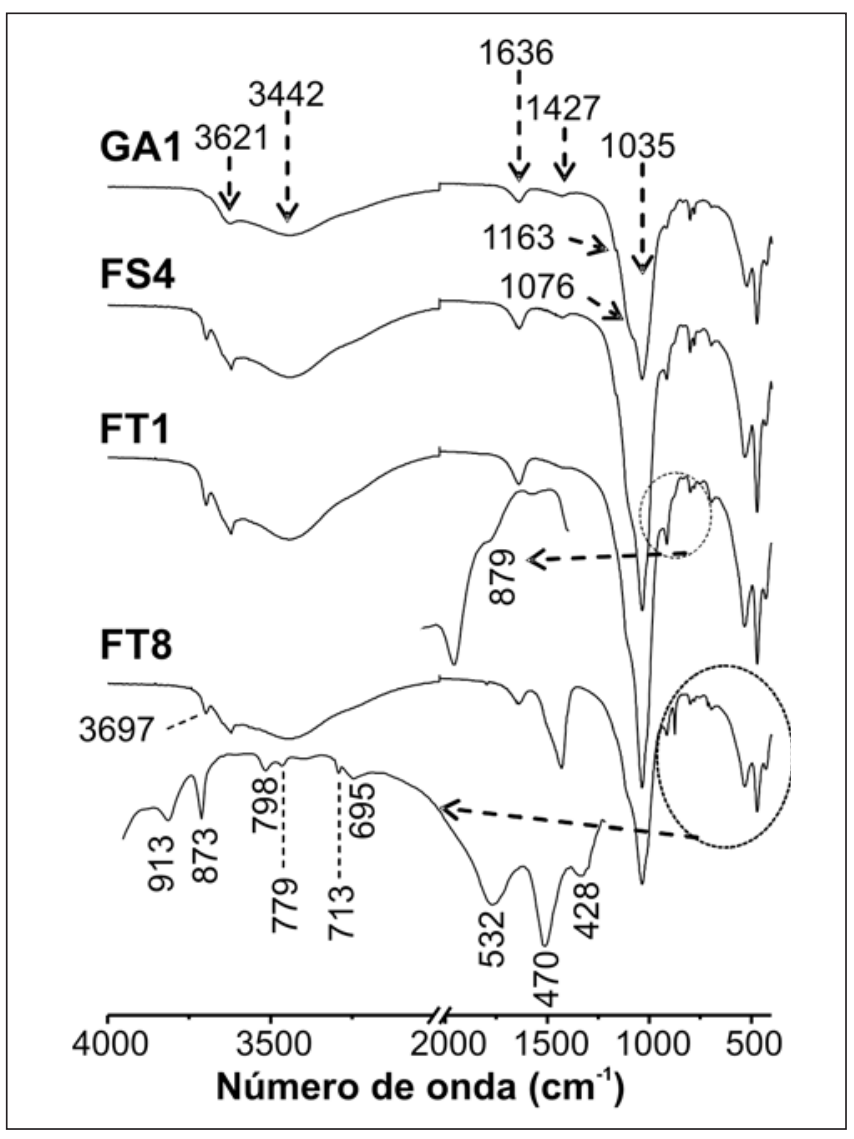

Figura 6 - Espectros do infra-vermelho da fração argila das quatro amostras selecionadas.

lho (Wilson, 1994). Dessa forma, a montmorilonita pode ser identificada nas bandas a 3621 e a $3442 \mathrm{~cm}^{-1}$ relativas à vibração de estiramento O-H, que é similar à encontrada na montmorilonita de Cheto (Wilson, 1994), que também tem um baixo teor em Fe. Outra banda característica da montmorilonita ocorre a $913 \mathrm{~cm}^{-1}$ e refere-se a vibração de deformação O-H em associação com a banda a $1.035 \mathrm{~cm}^{-1}$.

Para as outras esmectitas dioctaédricas da série beidelitanontronita, segundo trabalhos publicados por vários autores (Wilson, 1994; Goodman et alii, 1976; Farner \& Russel, 1967), as bandas de estiramento são encontradas em torno de 3632 a $3660 \mathrm{~cm}^{-1}$ para a beidelita e entre 3556 e $3581 \mathrm{~cm}^{-1}$ para a nontronita. Adicionalmente, na região de 1000 a $700 \mathrm{~cm}^{-1}$, duas bandas a 818 e $770 \mathrm{~cm}^{-1}$ são características da série beidelita-nontronita. Entretanto, essas bandas não foram encontradas nos resultados obtidos nessa pesquisa, o que sugere a não ocorrência de esmectitas da série beidelita-nontronita.

A curva da montmorilonita de Wyoming (Wilson, 1994, p. 26), que contém alguma substituição de $\mathrm{Al}^{3+}$ por $\mathrm{Fe}^{3+}$, é muito similar à da montmorilonita isenta de ferro. A principal diferença é a presença da banda de deformação O-H do grupo $\mathrm{AlFe}^{3+} \mathrm{OH}$ a $890 \mathrm{~cm}^{-1}$, que é diagnóstica da substituição do $\mathrm{Fe}$ na estrutura das esmectitas. Segundo este último autor, com o aumento do teor em Fe na montmorilonita, ou seja, com o aumento da substituição do $\mathrm{Al}^{3+}$ pelo $\mathrm{Fe}^{3+}$, a banda de deformação $\mathrm{AlFe}^{3+} \mathrm{OH}$ retrai de 890 a $870 \mathrm{~cm}^{-1} \mathrm{e}$, quando suficiente $\mathrm{Fe}$ está presente para dar o agrupamento $\mathrm{Fe}^{3+} \mathrm{Fe}^{3+} \mathrm{OH}$, como na nontronita, aparece a banda a $815 \mathrm{~cm}^{-1}$. Desta forma, nesse estudo, a banda a $879 \mathrm{~cm}^{-1}$ presente nas amostras FT1, FS4, GS1 caracteriza montmorilonita com substituição parcial do $\mathrm{Al}^{3+}$ pelo $\mathrm{Fe}^{3+}$. Já na amostra FT8, devido à presença de calcita, que absorve em torno de $880 \mathrm{~cm}^{-1}$, pode ocorrer interferência na banda da montmorilonita. Nessa amostra, as bandas a 1427, 873 e $713 \mathrm{~cm}^{-1}$ podem ser relacionadas à calcita.

A banda a $1636 \mathrm{~cm}^{-1}$ pode se referir à vibração de estiramento e de deformação de água de hidratação. Outras bandas a 1163 e a $1076 \mathrm{~cm}^{-1}$ correspondem às deformações axiais da ligação Si-O, tal como foi mostrado para a argila de Wyoming (Porto \& Aranha, 2002). A banda a $3697 \mathrm{~cm}^{-1}$ é típica da caulinita.

O dubleto a 798 e $779 \mathrm{~cm}^{-1}$, além da banda a $695 \mathrm{~cm}^{-1}$, identificam o quartzo. As bandas a 532, 470 e $428 \mathrm{~cm}^{-1}$ indicam a presença de feldspato (Van Der Marel \& Beutelspacher, 1976).

Valores de densidade, capacidade de troca catiônica (CTC) e superfície específica mostrados na Tabela 4 são próximos entre si. Esses resultados apresentam variações aquém dos recomendados na literatura (Gomes, 1986; Grim, 1962), o que sugere a interferência de outros argilominerais de baixa atividade, como caulinita e micas, além de outros não-argilominerais como quartzo e feldspatos. 
Tabela 4 - Valores de capacidade de troca catiônica (CTC), densidade e superfície específica pelos métodos BET e azul de metileno (AM), para as quatro amostras da fração argila.

\begin{tabular}{c|c|c|c|c}
\hline Amostra & $\begin{array}{c}\text { Densidade } \\
\left(\mathbf{g} / \mathbf{c m}^{-\mathbf{3}}\right)\end{array}$ & $\begin{array}{c}\text { CTC } \\
\left(\mathbf{m e q}^{\star} \mathbf{1 0 0 \mathbf { g } ^ { - \mathbf { 1 } } )}\right.\end{array}$ & $\begin{array}{c}\text { Superfície Específica } \\
\text { Externa }-\mathbf{B E T}\left(\mathbf{m}^{\mathbf{2}} \mathbf{g}^{-\mathbf{1}}\right)\end{array}$ & $\begin{array}{c}\text { Superfície Específica } \\
\text { Total }-\mathbf{A ~} \mathbf{~}\left(\mathbf{m}^{\mathbf{2}} \mathbf{g}^{-\mathbf{1}}\right)\end{array}$ \\
\hline GA1 & 2,31 & 58,80 & 36,42 & 439,85 \\
\hline FS4 & 2,13 & 54,00 & 46,76 & 403,94 \\
\hline FT1 & 2,27 & 60,00 & 33,77 & 448,83 \\
\hline FT8 & 2,30 & 56,50 & 43,89 & 422,64 \\
\hline
\end{tabular}

\section{Conclusões}

Após a realização das diferentes análises que permitiram fazer uma caracterização detalhada das argilas da Península de Santa Elena, podem-se ressaltar alguns aspectos importantes.

- Considerando os resultados mineralógicos, físicos e químicos e tendo em vista que as argilas da península pesquisada provêm da alteração de cinzas vulcânicas, pode-se concluir que estas são argilas do tipo bentonitas cálcicas, cujo principal componente pertence ao grupo das esmectitas dioctaédricas, sendo definida como montmorilonita ferruginosa.

- A presença de outros argilominerais como caulinita e traços de illita, embora em menores proporções, dificulta a caracterização da montmorilonita através das análises térmicas diferenciais. Entretanto, as bandas de vibração $\mathrm{O}-\mathrm{H}$, obtidas nos espectros do infravermelho, mostraram ser um importante critério para determinação das esmectitas ferruginosas.

- Depois de aplicadas as metodologias da EMBRAPA, para eliminação de matéria orgânica e carbonatos, seguidas da separação granulométrica, difratogramas de raios $\mathrm{X}$ da fração silte (não mostrados no artigo) confirmaram a presença de montmorilonita. Isto sugere que aglomerados de argilominerais estão sendo quantificados na fração silte. A metodologia utilizada, para esse material pesquisado, parece não ter alcançado alta eficiência.
- A microscopia eletrônica de varredura (MEV) confirmou que grande parte da fração argila mantém-se em forma aglomerada.

- Difratogramas das amostras com menores percentuais de fração argila mostraram conter calcita, mesmo na fração argila. Portanto o tratamento ácido não foi eficiente para eliminar os carbonatos presentes, que também podem estar presentes como cimentantes dos argilominerais.

- Os valores obtidos das análises de CTC e superfície específica mostram valores um tanto abaixo dos referenciados na literatura para montmorilonita pura, o que sugere a interferência dos demais minerais contidos nas amostras.

- O material pesquisado tem potencial para aplicações tecnológicas mais avançadas, como aquelas das bentonitas sódicas e cálcicas amplamente usadas na atualidade, tanto em seu estado natural, quanto após tratamentos de ativação (www.bentonit.com.br).

\section{Agradecimentos}

Ao CNPq do Brasil, pela bolsa de estudos durante o curso de doutorado. Ao Componente 6 do Programa VLIR/ ESPOL do Equador, pelo financiamento dos trabalhos de campo na Península de Santa Elena. Aos laboratórios da FICT da ESPOL do Equador e aos da Universidade Federal de Ouro Preto, pela realização das análises. Ao LEM (Laboratoire Environnement et Minéralurgie) da Escola Nacional de Geologia de Nancy,
França pelas análises de espectroscopia no infravermelho.

\section{Referências bibliográficas}

AMORIM, L. V., GOMES, C. M., LIRA, H. L. Bentotites from Boa Vista, Brazil: physical mineralogical and rheological properties. Materials Research, v. 7, n. 4, p. 583-593, 2004.

BRINDLEY G. W., BROWN G. Crystal structures of clay minerals and their $X$ ray identification. ( $2^{\mathrm{a}} \mathrm{Ed}$.). London: Mineralogical Society, 1980. 495p.

BRISTOW, C. R., HOFFSTETTER, R., FEININGER, T., HALL, M. T. Léxico estratigráfico del Ecuador. ( $2^{\mathrm{a}}$ Ed.). Paris: Centre National de la Recherche Scientifique, 1977.

BROWN, G. The X-ray identification and crystal structures of clay minerals. London: Mineralogical Society, 1961.

BRUNAUER, S. EMMETT, P. H., TELLER, E. Adsorption of gases in multimolecular layers. Journal of American Chemical Society, n. 60, p.309-319, 1938.

CODIGEM - Corporación de Desarrollo e Investigación Geológico - Minero Metalúrgica, Diagnóstico Ambiental en la Explotación de Canteras de Materiales de Construcción, Guayaquil. 1997. Relatório Técnico.

DEL ARCO, E. N., DUGAS, F., LABROUSE, B. Contribución al conocimiento estratigráfico, sedimentológico y tectónico de la región oriental de la Península de Santa Elena y Parte Sur de la Cuenca del Guayas. In: CONGRESSO ECUATORIANO DE INGENIEROS GEÓLOGOS DE MINAS Y PETRÓLEOS, 3. Guayaquil. Anais... 1983. 
Ana Mercedes Morales Carrera et al.

DIAMOND, S., KINTER, E. B. Surface areas of clays minerals as derived from measurements of glycerol retention. Clays and Clay Minerals, n. 5, p. 334-347, 1956.

DORFMAN, M. H. A plate tectonic model for development of the geology and estimation of potential petroleum reserves in Ecuador. Zagreb, 1976. 35p. Relatório Técnico.

DUGAS, F. Sedimentación y eventos tectónicos en el suroeste del Ecuador. In: CONGRESO ECUATORIANO DE GEOLOGÍA, MINAS Y PETRÓLEOS, 4. Quito. Anais... 1986.

EMBRAPA - Pesquisa Brasileira de Pesquisa Agropecuária. Manual de Métodos de Análises de Solo. ( ${ }^{\mathrm{a}}$ Ed.). Rio de Janeiro: Ministério da Agricultura e do Abastecimento, 1997. 212p.

FARNER, V. C., RUSSELL J. D. Infrared absorption spectrometry in clay studies. Clays and Clay Minerals, v. 15, n. 1, p.121-14, 1967.

GOMES, C. F. Argilas. O que são e para que servem. Lisboa: Fundação Calouste Gulbenkian, 1986. 456p.

GOODMAN, B. A. RUSSEL J.D., Fraser A.R. A Mössbauer and I.R. spectroscopic study of the structure of nontronite. Clays and Clay Minerals, n. 24, p. 53-59, 1976.

GREENE-KELLY, R. The identification of montmorillonoids in clays. Journal of Soil Science, n. 4, p. 233-237, 1953a.

GREENE-KELLY, R. Interpretation of D.T.A. diagrams. Clay Minerals Bulletin, n. 4, p. 233-237, 1953b.

GREENE-KELLY, R. The surface areas of montmorillonites. Clay Minerals Bulletin, n. 5, p. 392-400, 1964.

GRIM, R. E. Applied clay mineralogy. New York: McGraw Hill, 1962. 422p.

HOLDERBANK. Geological and chemical investigations and results of the overall raw prospection for the CEMEC. Cement Plant Project, Guaiaquil, 1974. 173p. (Relatório Técnico).

KAHR, G., MADSEN, F. T. Determination of the cation exchange capacity and surface area of bentonite, illite and kaolinite by methylene blue adsorption. Applied Clay Science, $\mathrm{n}$. 9, p. 327-336, 1995.

LONSDALE, P. Ecuadorian subduction system. American Association of Petroleum Geologists, 1978. 12p. (Traduzido por Stalin Benitez \& Jose Barquet).

MACKENZIE, R. C. The differential thermal investigation of clays. London: The Central Press, 1957. 456p.

MATO, L. F., NETO, O. P. C., PREDA, W. N. Procedimentos gerais para obtenção da distribuição granulométrica de sedimentos e rochas sedimentares. Ouro Preto: Departamento de Geologia, Universidade Federal de Ouro Preto, 1982. (Relatório de Análise Granulométrica).

MEHRA, O. P., JACKSON M. L. Iron oxide removal from soils by a dithionite-citrate system buffered with sodium bicarbonate. In: Proceedings of 7th National Clay Conference, Pergamon Press, New York. Anais... 1960. p. 317-327.

MIELENZ, R. C., SCHIELTZ N. C., KING M. E. Thermogravimetric analysis of clay and clay-like minerals. Clays and Clay Minerals, n. 2, p. 285-314, 1953.

MOORE, D. M., REYNOLDS, R. C. X-Ray diffraction and the identification and analysis of clay minerals. Oxford University Press. 1989.

MORALES-CARRERA, A. M. Caracterização mineralógica e tecnológica da argila de Guaiaquil, Equador. Ouro Preto: Departamento de Geologia, Universidade Federal de Ouro Preto, 2003. 89p. (Dissertação de Mestrado).

MORALES-CARRERA, A. M., VARAJÃO A. F. D., CÉSAR-MENDES, J. As argilas da jazida CENACA, em Guaiaquil. In: CONGRESSO BRASILEIRO DE GEOLOGIA, 41. Anais... João Pessoa, Brasil, 2003.

MUFF, R., KAPTEINAT, H. G. F. Ecuador's ceramic raw materials. Industrial Minerals, n. 253, p. 55-63, 1988.

PEJON, O. J., ZUQUETTE, L. V. Mapeamento geotécnico da folha de Piracicaba-SP (Escala 1:100.000) : Estudo de aspectos metodológicos, de caracterização e de apresentação dos atributos. São Carlos: Escola de Engenharia Civil, Universidade de São Paulo, 1992. (Tese de Doutorado).

PORTO J. P. P, ARANHA I. B. Caracterização cristaloquímica preli minar de bentonitas brasileiras. In: Série da X Jornada de Iniciação Científica. Anais... CETEM, 2002. Acesso em 10/06/2007. http://www.cetem.gov.br/serie_anais_X_jic.htmpublicacao/ serie_anais_X_jic_2002/Joao.pdf

SPENCER, N. Mapa geológico de la república del Ecuador. Escala 1:1.000.000. England. Cook, Hammond \& Kell Ltda. 1993.

VAN DER MAREL, H. W., BEUTELSPACHER, H. Atlas of Infrared Spectroscopy of Clay Minerals and their Admixtures. Amsterdan: Elsevier Scientific Publishing Company, Inc., 1976.

WILSON, M. J. Clay mineralogy: spectroscopic and chemical determinative methods. London: Chapman \& Hill, 1994. 367p.

Artigo recebido em 17/03/2007 e aprovadoo em 27/11/2007.

\section{REM - Revista Escola de Minas 72 anos divulgando CIÊNCIA. $\star * * * * *$ www.rem.com.br}

